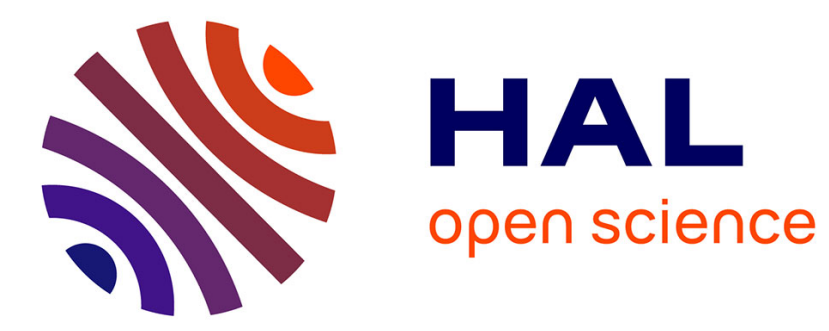

\title{
Cross-slip and glide in 001 planes of Al-Mg-Si alloy 6056
} François Delmas, Jérôme Majimel, Marie Vivas, Guy Molénat, Alain Couret, Armand Coujou

\section{To cite this version:}

François Delmas, Jérôme Majimel, Marie Vivas, Guy Molénat, Alain Couret, et al.. Cross-slip and glide in 001 planes of Al-Mg-Si alloy 6056. Philosophical Magazine Letters, 2003, 83 (5), pp. 289 - 296. 10.1080/095008303100 . hal-01851920

\section{HAL Id: hal-01851920 https://imt-mines-albi.hal.science/hal-01851920}

Submitted on 26 Oct 2020

HAL is a multi-disciplinary open access archive for the deposit and dissemination of scientific research documents, whether they are published or not. The documents may come from teaching and research institutions in France or abroad, or from public or private research centers.
L'archive ouverte pluridisciplinaire $\mathbf{H A L}$, est destinée au dépôt et à la diffusion de documents scientifiques de niveau recherche, publiés ou non, émanant des établissements d'enseignement et de recherche français ou étrangers, des laboratoires publics ou privés. 


\title{
Cross-slip and glide in $\{001\}$ planes of Al-Mg-Si alloy 6056
}

\author{
François Delmas $\dagger \S$, Jérôme Majimel $\dagger$, Marie Vivas $\ddagger$, Guy Molenat $\dagger$, \\ Alain Couret $\dagger$ and Armand Coujou $\dagger$ \\ $\dagger$ Centre d'Elaboration des Matériaux et d'Etudes Structurales, CNRS, \\ 29 rue Jeanne Marvig, BP 4347, 31055 Toulouse Cedex 04, France \\ $\ddagger$ Centre de Recherche Outillages Materiaux et Procedes, Ecole des Mines d'Albi \\ Carmaux, Campus Jarlard, 81013 Albi Cedex 09, France
}

\begin{abstract}
In-situ straining experiments and post-mortem observations in a transmission electron microscope have been performed between 20 and $170^{\circ} \mathrm{C}$ on $\mathrm{Al}-\mathrm{Mg}-\mathrm{Si}$ alloy 6056. Evidence is found for activation of cross-slip and occurrence of glide in the $\{001\}$ planes. These mechanisms occur more readily as temperature increases. Their existence is discussed in the light of microstructural characteristics of the alloy and an attempt is made to correlate them with macroscopic properties.
\end{abstract}

\section{$\S 1$. INTRODUCTION}

In the case of precipitation-hardened alloys, mechanisms by which dislocations can overcome fine precipitates were proposed years ago (Hirsch and Humphreys 1969, Gerold 1979). The most popular mechanisms are shearing and bypassing, for which there is experimental evidence (Merrick 1962, Gleiter and Hornbozen 1965, Hirsch and Humphreys 1969, Vivas et al. 1997). In this context, combining several techniques appears to be a useful approach.

(i) High-resolution electron microscopy (HREM) yields information on the structure, the morphology and the size of precipitates.

(ii) Post-mortem analyses of strained samples reveal the general features of dislocation microstructures generated by the deformation of bulk samples.

(iii) In-situ experiments performed inside the microscope allow direct observation of dislocation dynamics and the corresponding mechanisms of dislocation-precipitate interaction.

The present contribution is part of a general study of the deformation mechanisms and mechanical properties of $\mathrm{Al}-\mathrm{Mg}-\mathrm{Si}$ alloy (6056) based on such an association of investigations. Prior precipitation investigations carried out by HREM (Vivas et al. 1997, Delmas et al. 2003a,b) have found the following features.

(i) The precipitation hardening is due to fine-needle-shaped and lath-shaped precipitates elongated along the $\langle 100\rangle$ directions of the aluminium matrix.

§Email: delmas@cemes.fr. 
(ii) The average length of the needles and laths is $66 \mathrm{~nm}$ and their cross-sections are $7.0 \mathrm{~nm}$ and $6.5 \mathrm{~nm}$ respectively.

(iii) The precipitate density is $10^{17} \mathrm{~cm}^{-3}$.

The maximum force sustained by precipitates prior to shearing by dislocations has been evaluated (Vivas et al. 1997) and different micromechanisms have been identified and analysed as a function of temperature, such as the formation of planar dislocation loops (Orowan loops) or a spreading of large three-dimensional loops (Delmas et al. 2003b). The present letter focuses on the role of cross-slip and propagation in $\{001\}$ planes and their effect on the mechanical properties of the alloy.

\section{$\S 2$. EXPERIMENTAL DETAILS}

Alloy 6056 is cast and processed by Pechiney in the shape of polycrystalline sheets $1.5 \mathrm{~mm}$ thick. Table 1 gives the composition in weight percentages. The strengthening heat treatment consists in solutionizing at $550^{\circ} \mathrm{C}$, water quenching and finally a tensile plastic stretching $(2 \%)$ and tempering at $175^{\circ} \mathrm{C}$ for $8 \mathrm{~h}$ (T6 treatment). The resultant average grain size is $30 \mu \mathrm{m}$.

Both in-situ and post-mortem observations were performed in a JEOL 200CX electron microscope operating at $200 \mathrm{kV}$. Details of the in situ technique can be found elsewhere (Couret et al. 1993). We emphasize that, in this alloy, the strain fields due to precipitates are superimposed on those of the dislocations and can hinder the simultaneous imaging of dislocations and precipitates as described by Allen and Vander Sande (1978).

The yield stress of the present alloy 6056 has been found to be $350 \mathrm{MPa}$ at room temperature. As a comparison, the yield stress for other concurrent aluminium alloys at the same temperature is $324 \mathrm{MPa}$ for alloy $6013-\mathrm{T} 6$ and $310 \mathrm{MPa}$ for alloy 2024T3.

\section{§ 3. EXPERIMENTAL OBSERVATIONS}

\section{1. $\{001\}$ glide at room temperature}

Figure 1 shows a post-mortem weak-beam picture taken with a diffraction vector $\mathbf{g}=2 \overline{2} 0$ of the aluminium matrix. The foil was cut from a tensile specimen plastically strained at room temperature $\left(\varepsilon_{\text {plastic }}=2 \%\right)$. Dislocations are imaged with a white contrast, and observations under different diffracting conditions have shown that the Burgers vector of these dislocations is $\mathbf{b}= \pm(a / 2)[110]$. For these imaging conditions, the precipitates along dislocations are out of contrast because of the superimposition of the strain fields.

Dislocations indicated by white arrows exhibit a broken shape formed by successive segments parallel to the directions [010] and [100]. Taking into account that precipitates lie in $\{001\}$ planes, this observation is interpreted as an indicator of glide (at least over short distances) in these non-compact planes. With such a Burgers vector, the unique $\{001\}$ plane containing this vector is (001). Dislocations gliding in

Table 1. Chemical composition of the Al-Mg-Si alloy 6056 (Pechiney data).

\begin{tabular}{lcccccccc}
\hline $\begin{array}{l}\mathrm{Si} \\
(\mathrm{wt} \%)\end{array}$ & $\begin{array}{c}\mathrm{Mg} \\
(\mathrm{wt} \%)\end{array}$ & $\begin{array}{c}\mathrm{Cu} \\
(\mathrm{wt} \%)\end{array}$ & $\begin{array}{c}\mathrm{Mn} \\
(\mathrm{wt} \%)\end{array}$ & $\begin{array}{c}\mathrm{Fe} \\
(\mathrm{wt} \%)\end{array}$ & $\begin{array}{c}\mathrm{Zn} \\
(\mathrm{wt} \%)\end{array}$ & $\begin{array}{c}\mathrm{Zr} \\
(\mathrm{wt} \%)\end{array}$ & $\begin{array}{c}\mathrm{Cr} \\
(\mathrm{wt} \%)\end{array}$ & $\begin{array}{c}\mathrm{Ti} \\
(\mathrm{wt} \%)\end{array}$ \\
\hline 0.943 & 0.869 & 0.798 & 0.634 & 0.198 & 0.153 & 0.110 & 0.066 & 0.039 \\
\hline
\end{tabular}




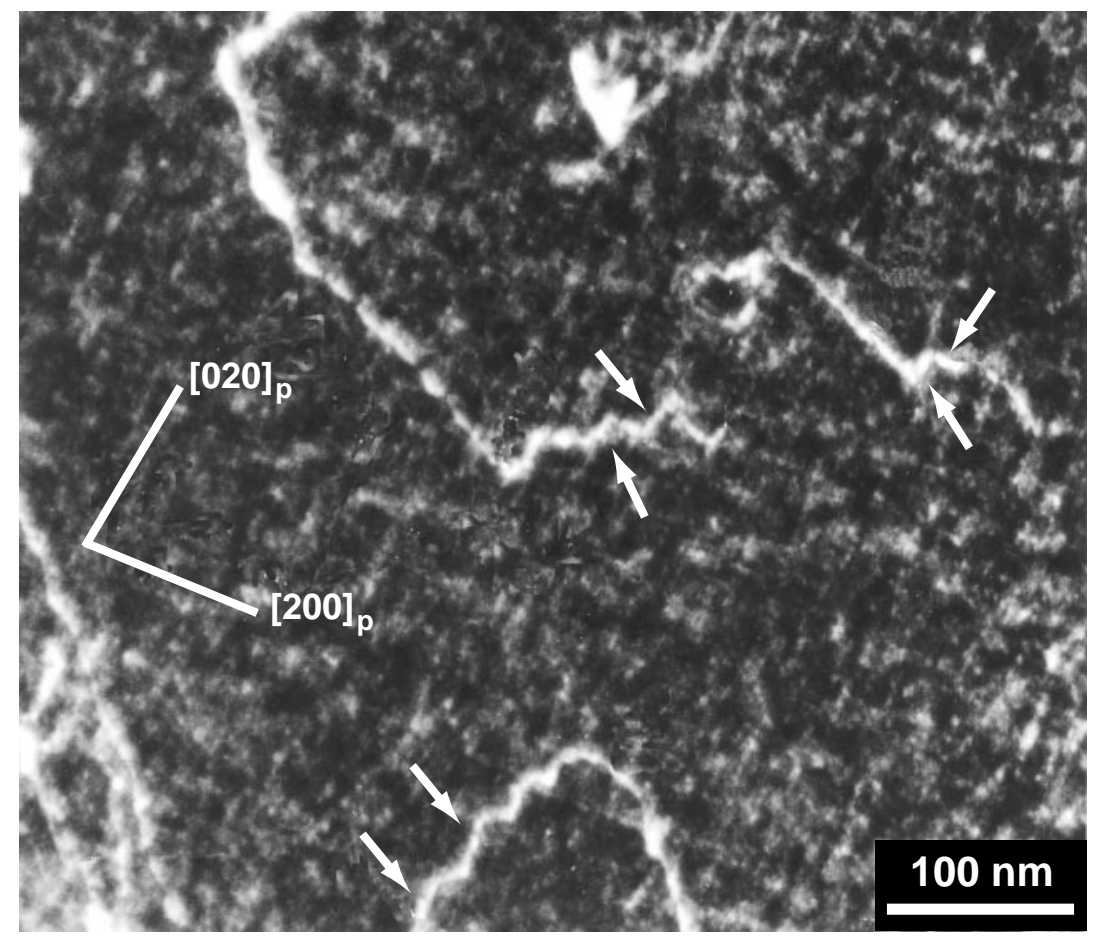

Figure 1. Post-mortem dark-field image of a specimen strained until $2 \%$ at room temperature. The diffraction vector is $\mathbf{g}=2 \overline{2} 0$ from the aluminium matrix. Projections in the observation plane of the $\langle 100\rangle$ directions are indicated. White arrows show segments of dislocations parallel to cubic directions.

this plane will thus lock along precipitates elongated along the [010] and [100] directions, consistent with the observation of figure 1. In general, segments of dislocations elongated along $\langle 100\rangle$ directions are not frequently observed at room temperature. This could be the reason why cubic glide has not been observed during in situ straining experiments.

\section{2. $\{001\}$ glide at higher temperatures}

Post-mortem transmission electron microscopy (TEM) observations and in-situ straining experiments performed at higher temperatures are described in the present section.

Figure 2 shows the microstructure of a specimen deformed at $2 \%$ in compression at $170^{\circ} \mathrm{C}$. This weak-beam image was taken with a $0 \overline{2} 0$ diffraction vector. Many segments of dislocations have the previously mentioned broken shape, indicating the activation of glide in $\{001\}$ planes (see for instance the segments between $\mathrm{A}$ and $\mathrm{B}$, or between $\mathrm{C}$ and $\mathrm{D}$ ). It is worth noting that these segments are much more frequently observed at this temperature than at $20^{\circ} \mathrm{C}$. As the Burgers vector of the involved dislocations is $\mathbf{b}= \pm(a / 2)[110]$, the corresponding $\{001\}$ cross-slip plane is (001): glide in this plane leads to an alignment of dislocations against the precipitates elongated along the [100] and [010] directions consistent with figure 2. 


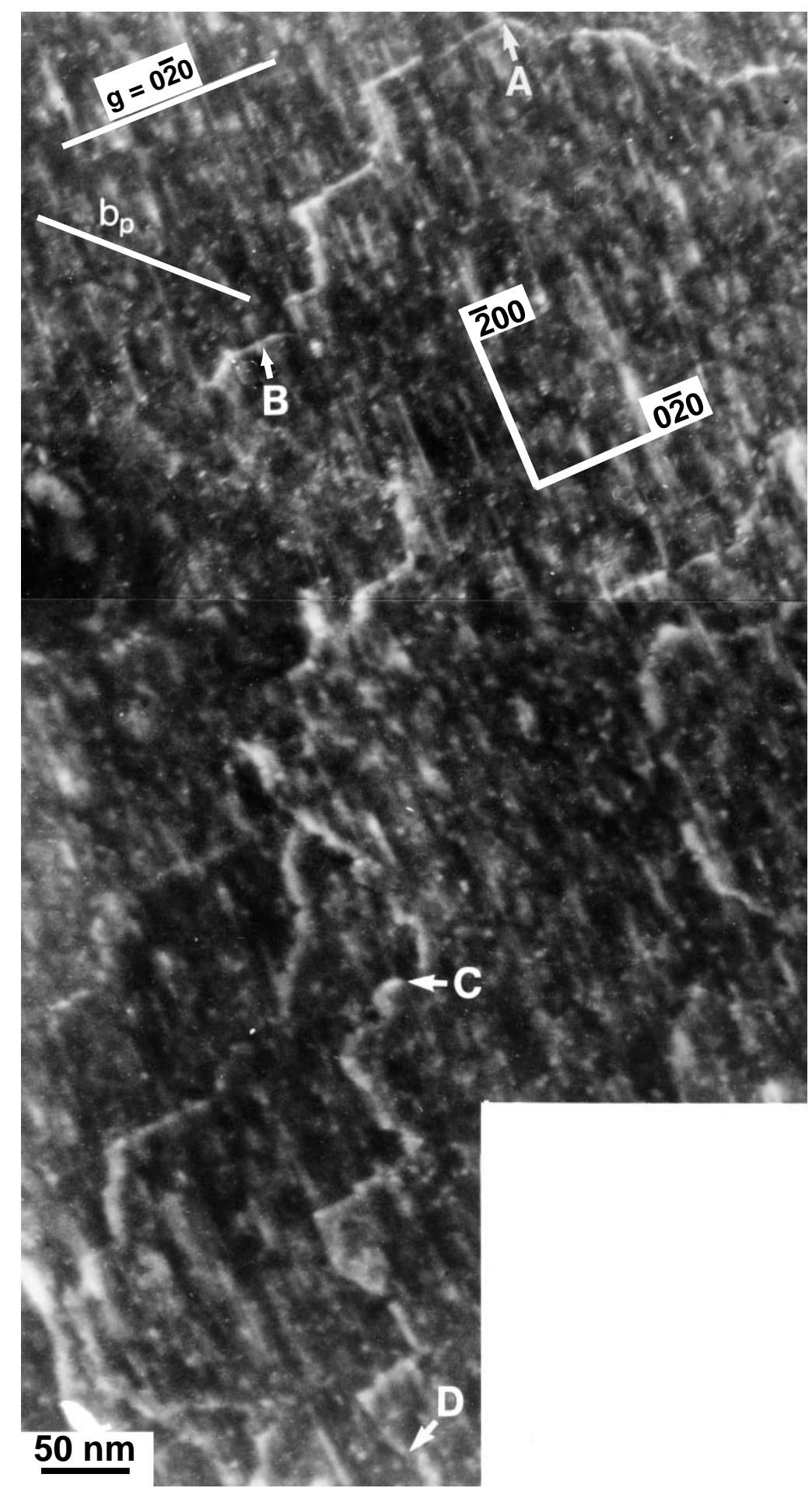

Figure 2. Post-mortem dark-field image of a specimen strained at $2 \%$ at $170^{\circ} \mathrm{C}$. The diffraction vector is $\mathbf{g}=0 \overline{2} 0$ from the aluminium matrix. Projections in the observation plane of the $\langle 100\rangle$ directions are indicated. 

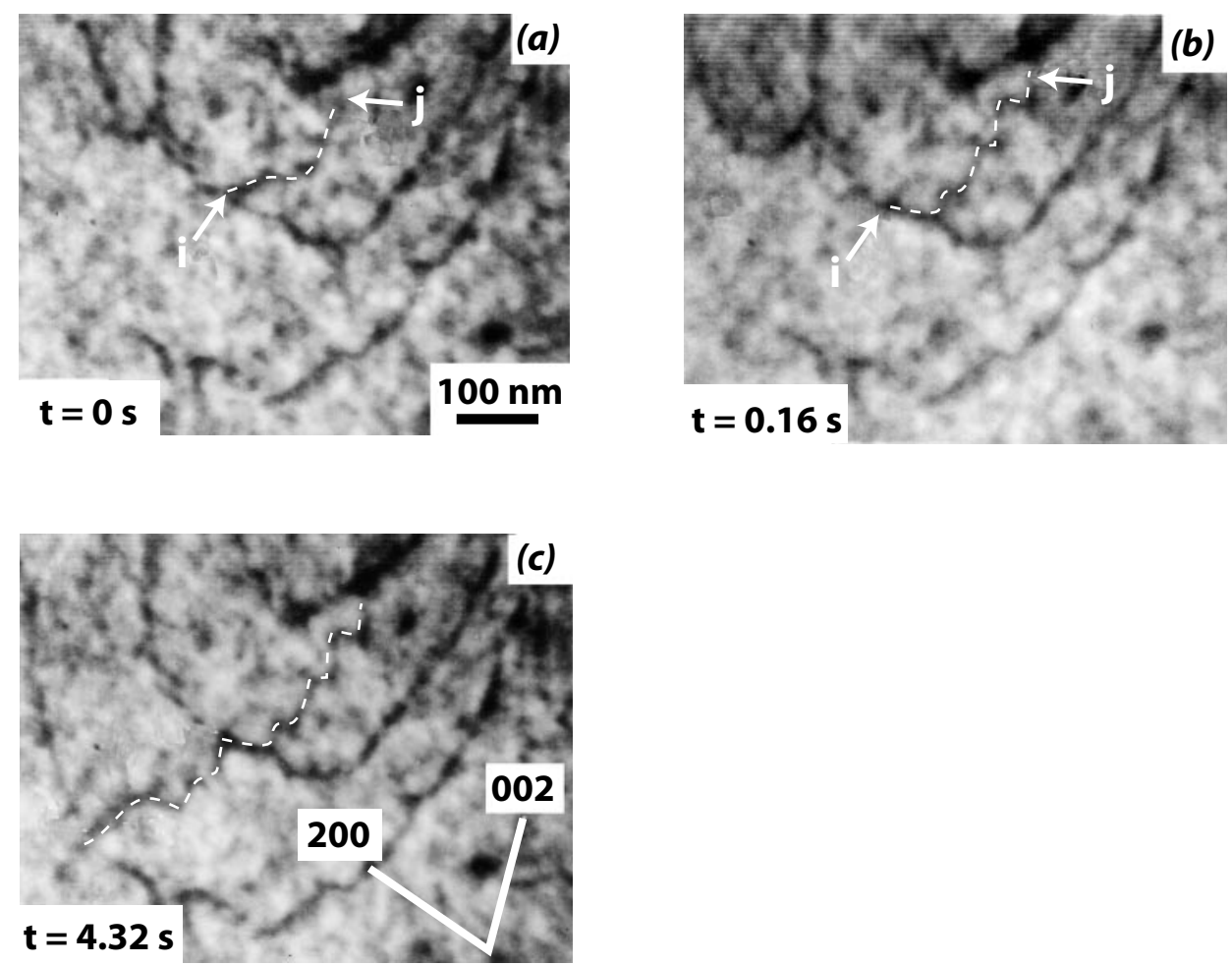

Figure 3. Dynamic sequence showing the propagation of a segment $i j$ of dislocation at $150^{\circ} \mathrm{C}(\mathbf{g}=1 \overline{1} 1)$. Projections in the observation plane of the $\langle 100\rangle$ directions are indicated.

Figure 3 displays a dynamic sequence showing a dislocation moving under stress at $150^{\circ} \mathrm{C}(\mathbf{g}=\overline{1} \overline{1} 0)$. Between figures $3(a)$ and $(b)$, the $i j$ dislocation glides and has a broken shape with segments parallel to the [100] and [001] directions. Part of this dislocation moves on between figures $3(b)$ and $(c)$. At the end of the sequence, the main part of the dislocation is locked in the (010) cross-slip plane. The Burgers vector is $\pm(a / 2)[\overline{1} 01]$, consistent with a glide in the $(010)$ plane, an alignment of the segments along the [100] and [001] directions and a diffracting vector $\mathbf{g}=\overline{1} \overline{1} 1$.

\section{$\S 4$. Discussion}

The main result of the present work is that, in this aluminium alloy, dislocations are able to cross-slip on to a $\{001\}$ plane and to glide in it. The cross-slip and glide are more frequently observed as the temperature is increased; both processes need the same physical event, that is the recombination of a screw segment, which is a thermally activated elementary mechanism. It should be emphasized that dislocations in aluminium alloys are not really dissociated into two separated partial dislocations. Consequently, it is better to speak of a core spreading into the $\{111\}$ planes.

Cross-slip or glide in $\{001\}$ plane has already been found in pure aluminium at higher temperatures and lower stress levels. During creep tests, Carrard and Martin (1987) have observed unstable $\{001\}$ glide (resulting from cross-slip events) from $180^{\circ} \mathrm{C}$ and primary $\{001\}$ glide for temperatures above $400^{\circ} \mathrm{C}$. In-situ experiments 
have shown that dislocation glide in this plane is controlled by a Peierls-type frictional force associated with core spreading of the dislocation out of the glide plane (Couret and Caillard 1988). These cross-slip and glide activities depend on the stacking-fault energy $\gamma$ which is high in aluminium $\left(\gamma=150 \mathrm{~mJ} \mathrm{~m}^{-2}\right.$ from HREM investigations (Mills and Stadelmann 1989)). For the case of alloy 6056 investigated in the present work, all the atoms present as solute atoms in the matrix can influence this value. If we refer to the work of Gallagher (1970), it appears that the addition of magnesium and silicon (the two main alloying elements) would have an opposite influence on the stacking-fault energy of pure aluminium. On the contrary, concerning the influence of temperature on $\gamma$, the derivative $\mathrm{d} \gamma / \mathrm{d} T$ would be positive according to Saka et al. (1983) for both an addition of 5 at.\% $\mathrm{Mg}$ or 5 at. $\% \mathrm{Si}$ in pure aluminium; this could indicate an increased easiness for cross-slipping as the temperature increases. Finally the observation of such cross-slip and $\{001\}$ glide activities at lower temperatures and higher stresses than in pure aluminium seems to indicate that the stress level is a key parameter for the recombination of the screw segments.

In the following we discuss the specific role of the precipitates as obstacles when $\{001\}$ glide operates and the effects on the mechanical properties of the cross-slip activity and non-compact glide.

\subsection{Precipitate population}

Following the work of Vivas et al. (1997) on the same alloy 6056, we consider for simplicity that all the precipitates are $66 \mathrm{~nm}$ long with a $3 \mathrm{~nm}$ diameter. The arrangement of precipitates is drawn in figure 4 . When gliding in a $\{111\}$ plane, dislocations cut forests of inclined precipitates (figure $4(a)$ ). If they glide in $\{100\}$ planes (figure $4(b)$ ), dislocations meet two types of precipitate, either perpendicular to the glide plane or parallel. Even if this last type is ten times less frequent, it constitutes a much more efficient obstacle for shearing because the section of precipitates viewed by dislocations is about 17 times higher for precipitates parallel to the glide plane than for those perpendicular to it. This probably explains the numerous observations of segments of dislocations locked along the precipitates lying along (001). Owing to the respective inclinations of precipitates, the ratio between the number of precipitates cutting the $\{111\}$ and $\{100\}$ planes is $N_{\{111\}} / N_{\{100\}}=1.6$. The ratio of the areas of precipitates in $\{111\}$ and $\{100\}$ planes is $A_{\{111\}} / A_{\{100\}}=1.7$. These lower values for the density and the area to be sheared in the case of $\{100\}$ planes probably favour gliding in the non-compact planes. It should, however, be emphasized that the strength of precipitates is also dependent on the overcoming mechanism and on the precipitate structure, two correlated parameters that are unfortunately not known at the present time.

\subsection{Consequences of cross-slip and $\{100\}$ glide on the mechanical properties}

The thermal activation of glide in $\{100\}$ planes and the subsequent existence of a new route for bypassing is probably the reason for the decrease in the yield stress $\sigma_{E}$ as a function of temperature (as illustrated in table 2) through the calculation of the slope $\Delta \sigma_{E} / \Delta T$ (this phenomenon is amplified above $125^{\circ} \mathrm{C}$ ). It should be emphasized that this effect could be of primary importance since alloy 6065 is a candidate for the fuselage skin of the future supersonic civil transport aircraft, the temperature of which can reach $130^{\circ} \mathrm{C}$. 


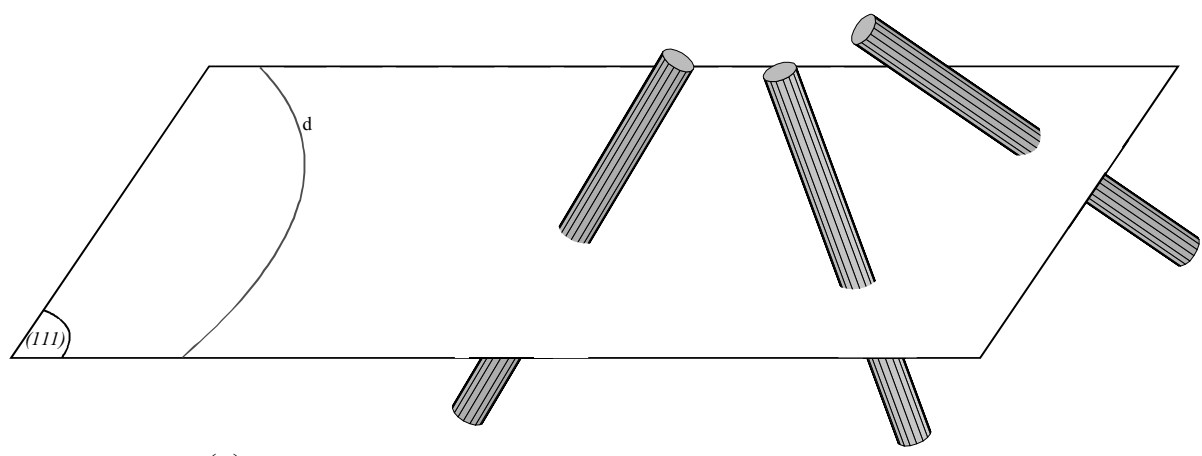

(a)

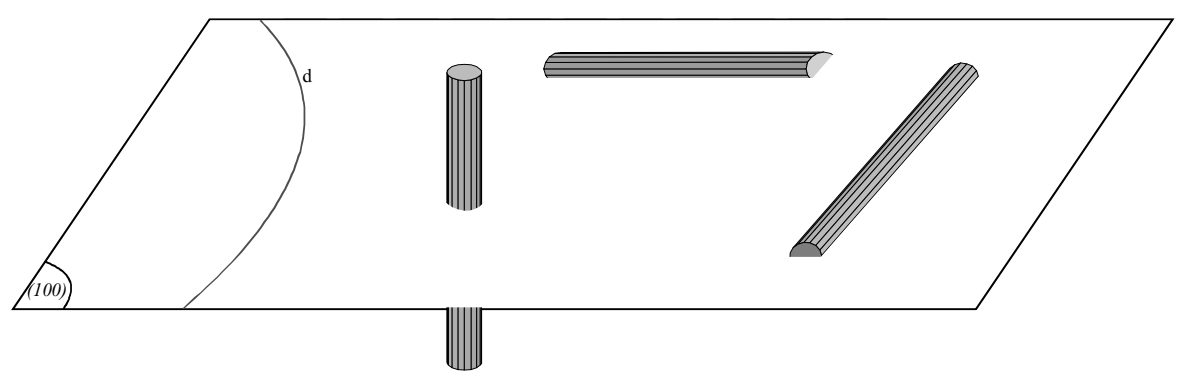

(b)

Figure 4. Illustration of how the precipitates intersect the gliding planes: $(a)$ a $\{111\}$ plane; (b) a $\{001\}$ plane.

Table 2. Yield stress and its derivative with respect to the temperature at different temperatures.

\begin{tabular}{rcc}
\hline$T$ & $\sigma_{E}$ & \\
$\left({ }^{\circ} \mathrm{C}\right)$ & $(\mathrm{MPa})$ & $\Delta \sigma_{E} / \Delta T$ \\
\hline-196 & 400 & -0.21 \\
20 & 355 & -0.38 \\
125 & 315 & -0.38 \\
170 & 285 & -0.67 \\
\hline
\end{tabular}

The ease of cross-slip can play a favourable role in the mechanical properties. In fact, the occurrence of intensive cross-slip avoids the formation of dislocation pileups, keeping away stress multiplication at their tip. The high-applied stress (350 MPa at $20^{\circ} \mathrm{C}$ ) corresponds to the stress necessary for propagating individual dislocations through precipitates. The elongated shape of precipitates also promotes a high stress level since it opposes bypassing mechanisms through short-range cross-slip.

\section{$\S 5$. CONCLUSION}

In the present letter, evidence for cross-slip and glide in $\{100\}$ planes in $\mathrm{Al}-\mathrm{Mg}-\mathrm{Si}$ alloy 6056 has been found by in-situ and post-mortem TEM analysis 
performed between 20 and $170^{\circ} \mathrm{C}$. These two elementary processes were observed to be thermally activated.

The activation of cross-slip and $\{100\}$ glide influences the mechanical strength of this alloy at different levels. Firstly, short range cross-slip in $\{111\}$ and $\{100\}$ planes, occurring at least from room temperature, avoids the formation of dislocation pileups and consequently prevent stress multiplication. Secondly, at higher temperatures, stable glide in $\{100\}$ planes will give dislocations the supplementary possibility of bypassing precipitates. This second effect is proposed to be at the origin of the strong decrease in the yield stress above $125^{\circ} \mathrm{C}$.

\section{REFERENCES}

Allen, R. M., and Vander Sande, J. B., 1978, Metal. Trans. A, 9A, 1251.

Carrard, M., and Martin, J. L., 1987, Phil. Mag. A, 56, 39.

Couret, A., and Caillard, D., 1988, Acta metall., 36, 2515.

Couret, A., Crestou, J., Farenc, S., Molénat, G., Clément, N., Coujou, A., and Caillard, D., 1993, Microsc. Microanal. Microstruct., 4, 153.

Delmas, F., Lours, P., Casanove, M. J., Couret, A., and Coujou, A., 2003a (to be published).

Delmas, F., Vivas, M., Lours, P., Casanove, M.J., Couret, A., and Coujou, A., 2003b, Mater. Sci. Engng, A340, 286.

Gallagher, P. C. J., 1970, Metall. Trans., 1, 2429.

Gerold, V., 1979, Dislocations in Solids, edited by F. R. N Nabarro, chapter 15 (Amsterdam: North Holland), p. 221.

Gleiter, H., and Hornbogen, E., 1965, Phys. Stat. sol., 12, 235.

Hirsch, P. B., and Humphreys, F. J., 1969, Physics of Strength and Plasticity, edited by A. Argon (Cambridge, Massachusetts: MIT Press).

Merrick, H. F., 1962, PhD Dissertation, University of Cambridge, Cambridge, UK.

Mills, M. J., and Stadelmann, P., 1989, Phil. Mag. A, 60, 355.

SaKa, H., Kondo, T., and Imura, T., 1983, Phil. Mag. A, 47, 859.

VIVAs, M., 1997, PhD Dissertation, Paul Sabatier University, Toulouse, France.

Vivas, M., Lours, P., Levaillant, C., Couret, A., Casanove, M.J., and Coujou, A., 1997, Phil. Mag. A, 76, 921. 